\title{
PELAKSANAAN SUPERVISI AKADEMIK PENGAWAS MADRASAH DALAM PENINGKATAN KOMPETENSI PEDAGOGIK GURU MI TARBIYATUSSIBYAN BANYUWANGI
}

\author{
Ahmad Aziz Fanani \\ IAI Ibrahimy Genteng Banyuwangi \\ fananiahmadaziz8g@gmail.com \\ Imam Wahyono \\ IAI Ibrahimy Genteng Banyuwangi \\ imamwahyono12031989@gmail.com
}

DOI: 10.35719/jieman.v3i1.43

\begin{abstract}
Abstrak
Penelitian ini mengkaji tentang pelaksanaan supervisi pengawas madrasah dalam peningkatan kompetensi pedagogik guru. Penelitian ini secara spesifik membahas tentang pelaksanaan supervisi akademik yang dilakukan oleh pengawas madrasah yang terdiri dari perencanaan kegiatan supervisi, pelaksanaan supervisi hingga sampai tindak lanjut. Pendekatan yang digunakan dalam penelitian ini adalah pendekatan kualitatif. Teknik pengumpulan data menggunakan pengamatan, wawancara, dan studi dokumen. Alat analisis data yang digunakan model interaktif yang terdiri dari pengumpulan data, reduksi data, penyajian data dan penarikan kesimpulan/verifikasi. Semenyara itu, keabsahan data dalam penelitian ini menggunakan trianggulasi sumber. Hasil penelitian ini pertama, perencanaan kegiatan supervisi akademik meliputi penyiapan instrumen supervisi, membuat rancangan pendekatan supervisi dan teknik supervisi dan penentuan waktu pelaksanaannya. Kedua, pelaksanaan kegiatan supervisi akademik dilakukan dengan
\end{abstract}


pendekatan kolaboratif dan teknik individual dan kelompok. Teknik individual yakni pertemuan secara individu dengan guru, sedangkan teknik kelompok dengan cara menghadirkan seluruh guru untuk diskusi sebagai proses kelompok dan tukar-menukar pengalaman. Sebagai tindak lanjut dari pelaksanaan sepervisi, yakni pengawas memberikan pembinaan kepada guru dengan cara memberikan pelatihan.

Kata Kunci: supervisi akademik, pengawas madrasah, kompetensi pedagogik

\section{Abstract}

The study examined the execution of the madrassa supervisor's supervision in increased pedagogical teachers' competence. The study specifically discussed the implementation of academic supervisions carried out by madrassa supervisors of supervision activities, the administration of supervision down to follow-up. The approach used in this study is a qualitative approach. Data-collecting techniques use observation, interviews, and document study. The data analysis tool used by interactive models consists of data collection, data reduction, data presentation and deduction deduction. Incidentally, the validity of the data in this research USES source tringgulation. The results of this first study, the planning of the academic supervision activities included the preparation of supervision instruments, the design of supervision approaches and supervision techniques and the timing of the execution. Second, the performance of academic supervision is carried out with collaborative approaches and individual and group techniques. An individual technique of meeting individually with teachers, while a group technique presents all teachers to discussion as a group process and an experience swap. As a follow-up to the exercise of a sense, the supervisor gives coaching to the teachers by training them.

Keywords: academic supervisions, madrassa supervisor, pedagogical competence

\section{Pendahuluan}

Kompetensi pengawas sekolah yang tersirat dalam Permendiknas Nomor 12 tahun 2007 tentang Standar Pengawas Sekolah/Madrasah menjelaskan bahwa kompetensi yang harus 
dimiliki oleh pengawas sekolah yakni kompetensi kepribadian, supervisi manajerial, supervisi akademik, evaluasi pendidikan, penelitian dan pengembangan. ${ }^{1}$ Selanjutnya dalam Permendikbud Nomor 15 Tahun 2018 tentang Pemenuhan Beban Kerja Guru, Kepala Sekolah, dan Pengawas Sekolah, Khusus Lampiran III yakni penyusunan program, pelaksanaan bimbingan, pemantauan implementasi SNP, pelaksanaan PKG dan PKS, pelaksanaan evaluasi, penyusunan program dan pelaksanaan dan evaluasi bimbingan latihan, pembimbingan pengawas sekolah muda dan madya (untuk pengawas utama). ${ }^{2}$

Pengawas madrasah merupakan komponen penting dalam tingkat satuan pendidikan yang dapat membantu Kemendikbud dan Pemerintah Daerah perihal pengelolaan dan pengkoordinasian pembelajaran pada tingkat satuan pendidikan. Hal yang lebih khusus yakni berkaitan tentang performan guru dalam pembelajaran. Hal ini sebagaimana yang diungkapkan oleh Abdul Hamid dkk yang menyebutkan bahwa dalam proses belajar mengajar peran supervisi kepala madrasah memiliki peran strategis dalam meningkatkan mutu pendidikan, di mana para guru didalam melaksanakan tugasnya merupakan ujung tombak dalam mensukseskan tujuan pendidikan nasional. ${ }^{3}$

Dalam hal ini kompetensi pedagogik yang harus dimiliki guru menjadi salah satu kompetensi yang penting dalam kegiatan pembelajaran. Dalam jurnal yang ditulis oleh Dyah Novita Purwandari Fakultas Ilmu Pendidikan, Universitas Negeri

1 Permendiknas Nomor 12 tahun 2007 tentang Standar Pengawas Sekolah/Madrasah.

${ }^{2}$ Permendikbud Nomor 15 Tahun 2018 tentang Pemenuhan Beban Kerja Guru, Kepala Sekolah, dan Pengawas Sekolah.

${ }^{3}$ Abdul Hamid dan Mohamad Ahyar Ma'arif, "Kepala Madrasah, Supervisi Akademik dan Kinerja Guru (Kasus di Madrasah Ibtidaiyah Sirajul Ulum Jatiurip Krejengan Probolinggo)." JIEMAN: Journal of Islamic Educational Management 1.1 (2019): 77-89. Lihat juga, Jasmani Asf \& Syaiful Mustofa, Supervisi Pendidikan: Terobosan Baru dalam Peningkatan Kinerja Pengawas Sekolah dan Guru. (Yogyakarta: Ar- Ruzz Media, 2013). 
Yogyakarta menjelaskan tentang pentingya kompetensi pedagogik guru dalam pembelajaran. Dalam kompetensi pedagogik ini meliputi pemahaman sikap peserta didik, pengembangan kurikulum, melaksanakan kegiatan pembelajaran yang humanis, memanfaatkan teknologi dalam aktivitas pembelajaran, pengembangan potensi (bakat) akademik, penguasaan wawasan dan landasan pembelajaran, menjalin komunikasi dengan peserta didik, penilaian belajar dan evaluasi belajar. Pada akhirnya akan sangat berkaitan dengan hasil belajar siswa. ${ }^{4}$

Secara nasional, kompetensi guru ini tertera pada Permendikbud Nomor 22 tahun 2020 tentang Renstra Kementerian Pendidikan dan Kebudayaan tahun 2020-2024 yakni pedagogik dan efektivitas pembelajaran para guru Indonesia yang terlihat masih perlu ada perbaikan. Guru masih bertindak sebagai penerus pengetahuan (transfer of knowledge), bukan sebagai seorang yang memberikan fasilitas pembelajaran. Banyak guru tidak memfokuskan pada pengembangan sikap/karakter serta membangkitkan semangat belajar. Uji Kompetensi Guru yang dilakukan terhadap guru-guru di Indonesia menunjukkan suatu hasil yang masih kurang dari target yang direncanakan. Nilai ratarata hasil UKG pada tahun 2019 nilai yang paling tinggi pada jenjang SD sebesar 54,8. Nilai rata-rata UKG 2019 tertinggi yang dicapai oleh guru jenjang SMA yaitu sebesar 62. Sedangkan ratarata, nilai UKG hanya 57 dari nilai maksimal 100.

Perihal di atas menunjukkan bahwa masih rendahnya kompetensi yang dimiliki oleh guru, begitu juga yang penulis temukan di MI Tarbiyatussibyan. Berdasarkan hasil observasi, masih terdapat guru yang senang menggunakan satu metode pembelajaran konvensional baik ceramah maupun tanya jawab dalam menyampaikan materi. Dari data tersebut, menggelitik penulis untuk melihat lebih dalam apa yang menjadi faktor penyebab tersebut. Padahal dalam lembaga pendidikan (madrasah/sekolah) pasti tardapat seorang pengawas yang memiliki

4 Dyah Novita Purwandari, "Pentingnya Kompetensi Pedagogik Guru dalam Proses Pembelaran di Sekolah Dasar.” Jurnal pendidikan (2018). 
peran memberikan pembinaan atau bantuan kepada guru dalam meningkatkan kualitas pembelajaran. Selain itu, penulis juga menemukan supervisor masih cenderung menitikberatkan pada aspek administratif dari peningkatan kompetensi pedagogik guru secara luas. Hal yang serupa penelitian yang dilakukan oleh Husain $^{5}$ tentang peranan pengawas pendidikan dalam meningkatkan kualitas pembelajaran guru di kota Kendari bahwa peran pengawas tidak menunjukkan adanya peningkatan kemampuan profesional yang membutuhkan bantuan dan bimbingan langsung dari pengawas terutama supervisi pembelajaran.

Dari beberapa latar belakang di atas maka penulisan dalam artikel penelitian ini memilih metode kualitatif dengan jenis pendekatannya yang bercorak deskriptif. Pendekatan ini, sangat relevan dalam upaya mengupas dan mendeskripsikan peran pengawas madrasah dalam melaksanakan supervisi akademik kepada guru. Berdasarkan pendekatan ini, maka pemaknaan yang dicari oleh peneliti bukanlah makna individual, melainkan makna universal yang disistematisasikan berdasarkan makna-makna yang berasal dari individu-individu yang menjadi dan berkaitan subjek penelitian ini. ${ }^{6}$

Berdasarkan kenyataan di atas maka sangat penting untuk mengkaji lebih dalam, khususnya dalam pelaksanaan supervisi akademik pengawas madrasah yang berkaitan dengan perencanaan, pelaksanaan dan tindak lanjut kegiatan supervisi akademik.

5 Syahri Nehru Husain, "Peranan Pengawas Pendidikan dalam Meningkatkan Kulaitas Pembelajaran Guru di kota Kendari.” SELAMI IPS Edisi Nomor 40 (2014), 15.

${ }^{6}$ John Creswell, Riset Pendidikan: Perencanaan, Pelaksanaan, dan Evaluasi Riset Kualitatif $\mathcal{E}$ Kuantitatif, Alih Bahasa Helly Prajitno \& Sri Mulyantini Soetjipto, (Yogyakarta: Pustaka Pelajar, 2015), 10. Lihat juga Matthew B. Miles and Alan M. Huberman, Qualitative Data Analysis, A Methods Sourcebook, $2^{\text {nd }}$ Edition. USA: Sage Publications. Terjemahan Tjetjep Rohindi Rohidi. (Jakarta: UIPress, 1981). Sugiyono, Metode Penelitian Pendidikan (Pendekatan kuantitatif, kualitatif, dan RED), (Bandung: Alfabeta, 2016). 


\section{Pembahasan}

\section{Perencanaan Kegiatan Supervisi Akademik Pengawas} Madrasah dalam Pembinaan Kompetensi Pedagogik Guru

Supervisi akademik merupakan serangkaian aktivitas membantu guru mengembangkan kemampuann tentang pengelolaan proses pembelajaran untuk mencapai tujuan pembelajaran. Melalui aktifitas supervisi akademik ini diharapkan dapat membantu guru dalam mengembangkan kemampuannya untuk mencapai tujuan pembelajaran. Maka dalam hal ini, sesuai dengan tujuan supervisi akademik sendiri, sebagaimana yang diungkapkan oleh Sergiovani terdapat tiga tujuan, yakni 1) penumbuhan motivasi, 2) pengawasan kualitas dan 3) pengembangan profesionalisme guru. ${ }^{7}$

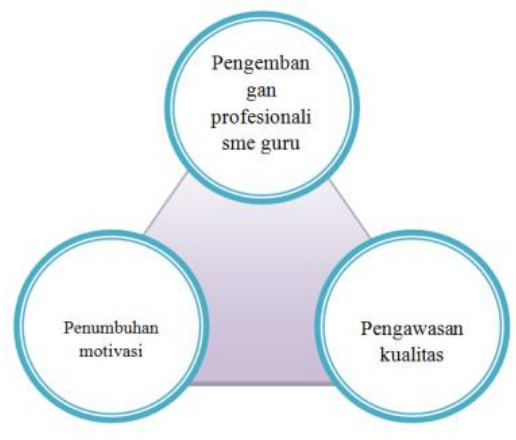

Gambar 1. Tujuan Supervisi Akademik

Dalam aktivitas supervisi akademik pengawas tentu tidak lepas dari perencanaan. Perencanaan supervisi akademik memiliki berbagai macam manfaat yang sangat berguna bagi supervisor. Perencanaan program supervisi akademik ini, dijadikan sebagai petunjuk dalam pelaksanaan dan pengawasan akademik, untuk menyamakan padangan/persepsi seluruh warga sekolah tentang program supervisi akademik, penjaminan penghematan dan keefektifan penggunaan sumber daya yang dimiliki oleh sekolah

${ }^{7}$ Siti Rodliyah, Supervisi Pendidikan \& Pembelajaran, (Jember: STAIN Press, 2014), 139 . 
seperti waktu, tenaga, dan bahkan biaya. ${ }^{8}$ Dalam hal ini, sebelum pengawas madrasah melaksanakan kegiatan supervisi akademik terlebih dahulu memberikan informasi kepada kepala madrasah melalui media seluler dan media WhatApp. Informasi tersebut berkenaan tentang jadwal pelaksanaanya agar supaya para guru menyiapkan perangkat pembelajaran. Hal ini dilakukan agar ketepatan dan efisiensi waktu yang digunakan dalam kegiatan supervisi berjalan sesuai rencana.

Dalam perencaanan ini setidaknya terdapat beberapa rumusan, tidak hanya pada perencanaan kapan supervisi dilaksanakan dan apa saja yang harus disipakan oleh guru. Akan tetapi kesepakatan antara kepala madrasah bersama pengawas yang meliputi perencanaan supervisi, merumuskan tujuan dan kriteria out put supervisi akademik, menyusun jadwal supervisi akademik, serta menentukan pendekatan dan teknik supervisi akademik. ${ }^{9}$ Sehingga kepala madrasah akan mudah memberikan informasi kepada guru tentang kegiatan sepervisi akademik. Kepala madrasah sebagai pemimpin pada suatu lembaga pendidikan bertanggung jawab penuh dalam kegiatan supervisi. Peran kepala madrasah dalam hal ini bertindak sebagai penyambung informasi dari pengawas sekaligus memberikan motivasi kepada guru. Peran kepala madrasah sebagai motivator merupakan salah satu kunci keberhasilan guru dalam melaksanakan pembelajaran, baik dari segi perencanaan, pelaksanaan maupun penilaian. Sebagaimana yaang diungkapkan oleh Wahjosumidjo, bahwa kepala madrasah mempunyai tugas sebagai motivator yaitu dapat memberikan motivasi kepada para tenaga pendidik dan peserta didik dalam melakukan berbagai tanggung jawabnya. ${ }^{10}$

8 Lantip Diat Prasojo dan Sudiyono, Supervisi Pendidikan, (Yogyakarta: Gava Media, 2002), 96.

${ }^{9}$ Heri Santoso dan Nusyirwan, Pengantar Supervisi Akademik, (Direktorat Jenderal Guru dan Tenaga Kependidikan, 2019), 10.

${ }^{10}$ Wahjosumidjo, Kepemimpinan Kepala Sekolah Tinjauan Teoritik dan Permasalahan, (Jakarta: Raja Grafindo, 2012), 110. 
Pada tataran perencanaan supervisi ini, pengawas sudah merencanakan serta menpersiapkan hal-hal yang harus dilakukan ketika pelaksanaan supervisi. Dalam penyusunan jadwal, pengawas madrasah sudah memiliki data siapa saja yang hendak akan disupervisi dan fokus masalahnya," sehingga tidak bisa hanya secara verbal saja, seorang pengawas memberikan informasi kepada kepada kepala madrasah. Akan tetapi secara tertulis perencanaan supervisi ini harus disepakati oleh kedunya. Agar supaya dalam perencanaan supevisi ini baik kepala madrasah, guru dan pengawas memiliki komitmen yang sama.

\section{Pelaksanaan Kegiatan Supervisi Akademik Pengawas Madrasah dalam Pembinaan Kompetensi Pedagogik Guru}

Dalam pelaksanaan supervisi, dibutuhkan sangat dibutuhkan suatu pendekatan yang sesuai dengan kebutuhan. Pendekatan supervisi sangat penting diperlukan agar pelaksanaan supervisi akademik di sekolah berjalan lancar. Pendekatan supervisi sangat tergantung pada tipologi guru yang akan disupervisi. Setiap guru memiliki karakteristik masing-masing dan bahkan berbeda-beda, sehingga dalam pelaksanaannya, juga membutuhkan suatu pendekatan yang berbeda-beda. Seorang guru yang mendapatkan layanan ini, akan mengalami proses belajar yang bermakna. Ia akan belajar dari pengalaman mengajarnya dan dengan bantuan seorang pengawas sebagai supervisor akan berusaha untuk memberikan penguatan dalam peningkatan aktifitas pembelajaran. Dengan demikian, pendekatan supervisi yang dipakai untuk membimbing guru harus berdasarkan pada prinsip dan teori belajar. Pengetahuan tentang teori belajar ini, dapat diperoleh dari disiplin ilmu psikologi belajar misalnya. Seorang pengawas/supervisor harus memiliki pemahaman yang memadai mengenai pendekatan-pendekatan supervisi. dalam hal ini, pendekatan supervisi secara umum dapat diklasifikasikan menjadi tiga, yaitu: “(1) Pendekatan langsung atau

\footnotetext{
${ }^{11}$ Heri Santoso dan Nusyirwan, Pengantar, 10.
} 
yang sering disebut dengan direktif, (2) Pendekatan tidak langsung atau Non-Direktif, dan (3) Pendekatan campuran (Kolaboratif). ${ }^{12}$

Dalam Undang-Undang Nomor 14 Tahun 2005 tentang Guru dan Dosen dijelaskan bahwa guru profesional harus menguasai kompetensi pedagogik, kompetensi kepribadian, kompetensi sosial dan kompetensi profesional, namun kompetensi pedagogik merupakan salah satu jenis kompetensi yang mutlak perlu dikuasai oleh guru. Dalam hal ini yang menjadi titik tekannya adalah kompetensi pedagogik. Sejalan dengan pengertian tersebut Hakim mengatakan, kompetensi pedagogik atau akademik ini merujuk kepada kemampuan guru untuk mengelola proses belajar mengajar, termasuk didalamnya perencanaan dan pelaksanaan, evaluasi hasil belajar mengajar dan pengembangan siswa sebagai individu-individu. ${ }^{13}$

Dalam pelaksanaan supervisi akademik tidak lepas dari komitmen peran pengawas sebagai pembina para guru. Sebagai pembina para guru tentu seorang pengawas sebagai supervisor bertindak luwes kepada guru. Dalam hal ini supervisi harus kreatif dan konstruktif, setiap guru akan merasa terdorong untuk mengembangkan kompetensinya apabila supervisi mampu menciptakan suasana kerja yang harmonis, bukan melalui cara-cara menakutkan bahkan membuat guru menjadi tertekan. ${ }^{14}$ Wahyudi menjelaskan delapan prinsip yang dapat digunakan dalam melakukan aktifitas supervisi. Prinsip-prinsip tersebut mencakup sistematis, objektif, realistik, antisipatif, membangun, kreatif, kerjasama, dan kekeluargaan. ${ }^{15}$ Hal ini senada dengan ungkapan pengawas MI Tarbiyatussibyan Sumberkepuh Tegaldlimo bahwa kita semua posisinya sama, yakni sama-sama belajar. Dari ungkapan

${ }^{12}$ Piet A.Sahertian, Konsep Dasar \& Teknik Supervisi Pendidikan dalam Rangka Pengembangan Sumberdaya Manusia, (Jakarta: Rineka Cipta, 2010), 46.

${ }^{13}$ Lukmanul Hakim, Perencanaan Pembelajaran, (Bandung: Wacana Prima, 2009), 243.

${ }^{14}$ Frans Mataheru, Prinsip-prinsip dan Teknik Supervisi Pendidikan, (Surabaya: Usaha Nasional, 1981), 16.

${ }^{15}$ Imam Wahyudi,Pengembangan Pendidikan, (Jakarta: Prestasi Pustakarya, 2012), 48-49. 
tersebut, proses kegiatan supervisi berjalan dengan efektif dan efisien. Sehingga para guru sangat senang apabila diberikan masukan dan gurupun dengan senang hati untuk bercerita tentang permasalahan yang sedang dihadapinya. Dengan terbangunnya prinsip kekeluargaan tersebut pengawas madrasah lebih leluasa dalam memberikan pembinaan.

Perihal pendekatan supervisi yang diterapkan oleh pengawas yakni menggunakan pendekatan kolaboratif, artinya pada pendekatan ini baik supervisor maupun guru bersama-sama sepakat untuk menetapkan struktur, proses dan kriteria dalam melaksanakan proses percakapan terhadap masalah yang dihadapi guru. Kegiatan yang dilakukan yakni menjelaskan, menyajikan, mengarahkan, memberi contoh, menetapkan tolak ukur, mendengarkan, memberi penguatan, memecahkan masalah dan negosiasi.

Kunjungan pengawas madrasah lebih sering dan lebih banyak membantu guru baik melalui kegiatan pembinaan, pembimbingan, penilaian mapun pelatihan. Di madrasah ini sudah terbentuk budaya menghormati dan menjamu tamu dengan baik, siapa pun yang datang ke madrasah ini selalu disambut dan dilayani dengan baik mulai dari staf TU, guru-guru sampai dengan kepala madrasahnya sendiri. Kehadiran pengawas selalu disambut dengan senang bahkan dengan penuh keakraban, para guru bersemangat melakukan konsultasi seputar permasalahan pembelajaran yang sedang dihadapinya. Pengawas dan guru sudah menjalin komitmen bahwa hubungan di antara keduanya adalah mitra kerja. Sehingga pengawas madrasah sangat leluasa dalam melaksanakan supervisi akademik dan para guru sangat terbuka untuk menyampaikan permasalahan yang dihadapinya.

Kemampuan pengawas dalam menjalankan tugasnya sebagai supervisor pendidikan juga tercermin dalam penentuan materimateri supervisi, yakni terdiri dari perencanaan program meliputi: materi supervisi yang berkaitan dengan administrasi pembelajaran yang harus dibuat oleh guru antara lain program tahunan, program semester, silabus, Rencana Pelaksanaan Pembelajaran (RPP), 
kalender pendidikan, jurnal mengajar guru, daftar nilai, Kriteria Ketuntasan Maksimal (KKM), dan presensi siswa. Sedangkan materi yakni menyangkut materi pelaksanaan KBM diarahkan pada materi pengelolaan kelas mulai dari kegiatan membuka, kegiatan inti, dan penilain pembelajaran. Pada sisi ini, pengawas lebih menekankan pada sisi administrasi guru, yakni RPP. Seperti ungkapan pengawas kepada guru yaitu saat ini RPP sudah tidak rumit lagi, karena lebih simpel dari pada sebelumnya. Namun meskipun sempel harus sesuai dengan pembelajaran saat ini, yakni pembelajan mencocokkan antara metode pembelajaran dengan materinya.

Teknik pelaksanaan supervisi yang dilakukan oleh pengawas kepada para guru dilakukan secara individual dan kelompok. Dalam kegiatan individual yakni menitikberatkan pada pertemuan individual dengan guru kelas dan guru mata pelajaran dari pada observasi kelas. Dalam pertemuan tersebut, pengawas madrasah bertanya kepada guru berdasarkan instrumen yang telah dibuat. Selanjutnya pengawas madrasah berdiskusi kepada guru tentang administasi pembelajaran yang harus dan wajib dibuat oleh guru. Hal ini senada dengan Sagala bahwa "komunikasi pribadi merupakan suatu cara dalam pemberian bantuan kepada guru dengan mengadakan komunikasi tentang permasalahan yang dihadapi guru." Pertemuan pribadi ini, antara guru dengan supervisor membicarakan permasalahan khusus yang dihadapi guru. ${ }^{16}$

Selanjutnya, perihal tentang pelaksanaan supervisi secara berkelompok dilakukan dengan mengadirkan para guru pada kegiatan pembinaan. Pembinaan yang dilakukan oleh pengawas madrasah tidak hanya diikuti oleh para guru dari MI Tarbiyatussibyan saja, melainkan juga menghadirkan guru dari madrasah yang lain. Saat supervisor menemukan beberapa permasalahan yang sama dihadapi hampir seluruh guru, maka sangat tidak efektif bila dilakukan pembicaraan individual, oleh karena itu akan dibahas dalam rapat guru. Selanjutnya dalam

16 Syaiful Sagala, Supervisi Pembelajaran dalam Profesi Pendidikan, (Bandung: Alfabeta, 2002) 190. 
pertemuan ini, pengawas madrasah memberikan wawasan kepada guru seputar permasalahan umum tentang administrasi pembelajaran, khususnya dalam merancang RPP yang didalamnya memuat hal-hal dalam proses pembelajaran. Selain itu agar ada jalinan komunikasi antara guru satu dengan yang lainnya, serta saling memberikan masukan dan saling bertukar pengalaman bahkan dengan guru lintas madrasah.

Pengawas madrasah sebagai narasumber dalam pembinaan tersebut memberikan contoh dalam pembuatan RPP. Selanjutnya, para guru merancang sendiri sesuai dengan masing-masing bidang mata pelajaran. Untuk melihat hasil dari bimbinaan RPP tersebut, pengawas madrasah mencari informasi kepada kepala madrasah dalam tataran praktis pelaksanaan pembelajaran di kelas serta melihat hasil belajar siswa. Selain itu, tindak lanjut hasil supervisi yang dilakukan oleh pengawas yaitu dengan cara mengadakan pelatihan, pelatihan yang pernah dilakukan yaitu pelatihan penyusunan RPP yang dibimbing langsung oleh pengawas dan diikuti oleh guru.

Dalam pelaksanaan sepervisi ini yaitu menggunakan pendekatan kolaboratif dan teknik individual serta kelompok. Dengan teknik individual ini yang dilakukan melalui tanya jawab dengan guru dan diskusi dengan guru terdapat ini terdapat beberapa kelemahan. Karena pengawas tidak mengetahui secara detail bagaimana guru melaksanakan pembelajaran berdasarkan rencana yang tersusun pada RPP. Selain itu pengawas hanya mendengarkan keluh-kesah apa yang disampaikan guru, sehingga tidak tau apa yang diinginkan dari siswa, suasana kelas dan lain sebaginya.Tindak lanjut yang dilakukan oleh pengawas yaitu dengan cara mengadakan pelatihan bagi guru. Akan tetapi pelatihan yang diadakan oleh pengawas kurang spesifik, karena pelatihan tersebut diperuntukkan kepada seluruh guru, bukan kepada guru yang nilai hasil supervisinya rendah atau kurang. Dalam tataran konsep, sebelum tindak lanjut dilaksanakan seorang pengawas seharusnya melaksanakan analisis data. Secara umum siklus kegiatan supervisi akademik sebagai berikut: 


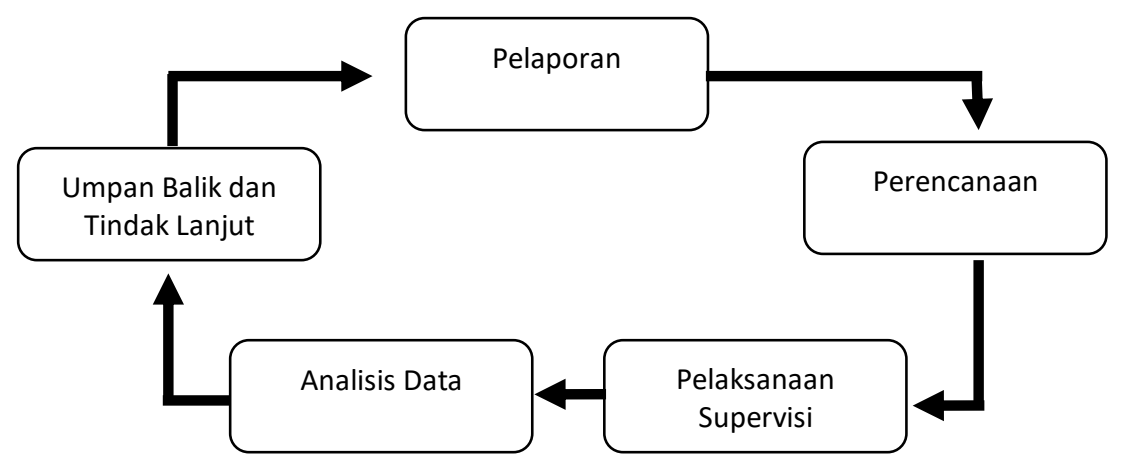

Gambar 2. Silkus Supervisi Akademik ${ }^{17}$

Berdasarkan data di atas, aktifitas analisis data belum dilaksanakna oleh pengawas madrasah. Sehingga dalam pelaksanaan tindak lanjut kurang spesifik guru yang hendak diberikan penguatan dan pembinaan. Semua guru mengikuti kegiatan pelatihan sebagai untuk peningkatan dalam pembuatan rancangan pembelajaran.

\section{Simpulan}

Perencanaan kegiatan supervisi akademik pengawas madrasah dalam peningkatan kompetensi pedagogik guru yang dilakukan oleh pengawas madrasah di MI Tarbiyatussibyan Sumberkepuh Tegaldlimo Banyuwangi yaitu membuat target dan tujuan, menyiapkan instrumen supervisi, membuat rancangan pendekatan supervisi, teknik supervisi dan penentuan waktu pelaksanaannya. Dalam penentuan waktu pelaksanaan supervisi akademik yang dilaksanakan oleh pengawas yakni dengan cara memberikan informasi kepala kepala madrasah melalui media seluler atau media WhatApp.

\footnotetext{
${ }^{17}$ Heri Santoso dan Nusyirwan, Pengantar, 8.
} 
Pelaksanaan kegiatan supervisi akademik pengawas madrasah dalam peningkatan kompetensi pedagogik guru dilakukan dengan pendekatan kolaboratif. Sedangkan teknik supervisi yang dilakukan yakni teknik individual dan kelompok. Dalam kegiatan individual yakni pertemuan individual dengan guru kelas dan guru mata pelajaran. Dalam pertemuan tersebut, pengawas madrasah bertanya dan berdiskusi kepada guru berdasarkan instrumen yang telah dibuat. Sedangkan supervisi secara berkelompok dilakukan dengan mengadirkan para guru, yakni melakukan rapat antara pengawas madrasah dan para guru. Selanjutnya pengawas madrasah memberikan pembinaan serta diskusi sebagai proses kelompok dan tukar-menukar pengalaman tentang permasalahan yang dihadapi guru dan memberikan solusinya. Belum ada analisis data secara detail sebagai data untuk pelaksanaan tindak lanjut. Sehingga tindak lanjut dari kegiatan supervisi, dilakukan dengan cara memberikan pelatihan langsung oleh pengawas kepada seluruh guru, bukan guru yang mendapatkan penilaian dengan hasil kurang atau cukup.

\section{Daftar Pustaka}

Asf, Jasmani \& Syaiful Mustofa. Supervisi Pendidikan: Terobosan Baru dalam Peningkatan Kinerja Pe ngawas Sekolah dan Guru. Yogyakarta: Ar- Ruzz Media, 2013.

Creswell, John. Riset Pendidikan: Perencanaan, Pelaksanaan, dan Evaluasi Riset Kualitatif \& Kuantitatif, Alih Bahasa Helly Prajitno \& Sri Mulyantini Soetjipto. Yogyakarta: Pustaka Pelajar, 2015.

Hakim, Lukmanul. Perencanaan Pembelajaran. Bandung: Wacana Prima, 2009.

Hamid, Abdul, dan Mohamad Ahyar Ma'arif. "Kepala Madrasah, Supervisi Akademik dan Kinerja Guru (Kasus di Madrasah Ibtidaiyah Sirajul Ulum Jatiurip Krejengan 
Probolinggo)." JIEMAN: Journal of Islamic Educational Management 1.1 (2019): 77-89.

Mataheru, Frans. Prinsip-prinsip dan Teknik Supervisi Pendidikan. Surabaya: Usaha Nasional, 1981.

Miles, Matthew B. and Alan M. Huberman. Qualitative Data Analysis, A Methods Sourcebook, $2^{\text {nd }}$ Edition. USA: Sage Publications. Terjemahan Tjetjep Rohindi Rohidi. Jakarta: UI-Press, 1981.

Permendikbud Nomor 15 Tahun 2018 tentang Pemenuhan Beban Kerja Guru, Kepala Sekolah, dan Pengawas Sekolah.

Permendiknas Nomor 12 tahun 2007 tentang Standar Pengawas Sekolah/Madrasah.

Prasojo, Lantip Diat dan Sudiyono. Supervisi Pendidikan. Yogyakarta: Gava Media, 2002.

Purwandari, Dyah Novita "Pentingnya Kompetensi Pedagogik Guru dalam Proses Pembelaran di Sekolah Dasar." Jurnal pendidikan (2018).

Rodliyah, Siti. Supervisi Pendidikan \& Pembelajaran. Jember: STAIN Press, 2014.

Sagala, Syaiful. Supervisi Pembelajaran dalam Profesi Pendidikan. Bandung: Alfabeta, 2002.

Sahertian, Piet A. Konsep Dasar E Teknik Supervisi Pendidikan dalam Rangka Pengembangan Sumberdaya Manusia. Jakarta: Rineka Cipta, 2010.

Sugiyono. Metode Penelitian Pendidikan (Pendekatan kuantitatif, kualitatif, dan RED). Bandung: Alfabeta, 2016.

Santoso, Heri dan Nusyirwan. Pengantar Supervisi Akademik. Jakarta: Direktorat Jenderal Guru dan Tenaga Kependidikan, 2019.

Undang-Undang Nomor 14 Tahun 2005 tentang Guru dan Dosen. 
JIEMAN: Journal of Islamic Educational Management

Wahjosumidjo. Kepemimpinan Kepala Sekolah Tinjauan Teoritik dan Permasalahan. Jakarta: Raja Grafindo, 2011.

Wahyudi, Imam. Pengembangan Pendidikan. Jakarta: Prestasi Pustakarya, 2021.

Husain, Syahri Nehru. "Peranan Pengawas Pendidikan dalam Meningkatkan Kulaitas Pembelajaran Guru di kota Kendari. SELAMI IPS. 